\title{
THREE LARGE TRUCK CRASH CATEGORIES: WHAT THEY TELL US ABOUT CRASH CAUSATION
}

\author{
Ronald R. Knipling \\ Human Factors \& Traffic Safety Consultant \\ Arlington, Virginia, USA \\ Email: tbsafety@aol.com
}

\begin{abstract}
Summary: Large Truck Crash Causation Study (LTCCS) data is used to compare three categories of crash involvements: truck single-vehicle (SV) involvements, multi-vehicle (MV) involvements in which the truck has been assigned the critical reason $(\mathrm{CR})$, and $\mathrm{MV}$ involvements in which the other vehicle $(\mathrm{OV})$ has been assigned the CR. These three categories represent distinctly different causal contributions by truck drivers to the crash, with SV involvements having the greatest truck driver impairment and misbehavior. Surprisingly, paired comparisons of the three categories indicate that truck SV and truck-CR MV crash involvements were the most dissimilar in their causal profiles. Factors associated with truck SV crash involvements include non-use of safety belts, driver unfamiliarity with roadways, vehicle failures, lack of prior sleep, 16+ hours awake, and early morning driving. Dense traffic situations (e.g., rush hours) make trucks more likely to be at-fault in MV crashes. Many other factors were not associated with differences among the categories, suggesting no differential effect on truck driver safety performance, even though they might affect risk generally. Among fatigue-related factors, those related to sleep and alertness physiology were linked to SV crashes, while those related only to Hours-of-Service (HOS) work rules were not.
\end{abstract}

\section{OBJECTIVE \& METHOD}

This "data mining" analysis employs statistics on crash causation, characteristics, conditions of occurrence, and associated factors from the LTCCS. The LTCCS (Starnes, 2006) employed indepth post hoc investigations and reconstructions of 963 large truck crashes involving 1,123 trucks and 837 other vehicles. Crashes were selected based on a stratified sample of large truck crashes causing one or more fatalities or injuries. Cases were assigned weights to generate nationally representative statistical profiles in a manner similar to the General Estimates System. LTCCS data variables provide detailed descriptions of the physical events of each crash, along with extensive information about drivers, vehicles, locations, weather, and roadways.

This paper re-examines data from an earlier LTCCS study (Knipling and Bocanegra, 2008), which primarily compared crashes involving Combination-Unit Trucks (CTs or tractorsemitrailers) to those of Single-Unit Trucks (STs or straight trucks). The analysis examined 44 variables relating to crash characteristics, conditions of occurrence, key causal variables, and associated factors. This paper focuses on a perspective that was secondary in the original work, but which actually provided more provocative findings; that is, comparisons among different crash categories. In this paper, LTCCS statistics are examined for three crash categories: 
- Truck SV crash involvements.

- MV crash involvements where the truck was assigned the CR ("at-fault").

- MV crash involvements where the OV was assigned the CR.

These categories represent three distinctly different causal contributions by the truck driver (or truck). SV crashes occur due to loss of vehicle control, either resulting in a road departure, rollover, or jackknife. They often involve egregious unsafe driving acts, driver impairment, or vehicle failures (Knipling, 2009). Truck-CR MV crashes can be due to these same factors, but far more often they are due to driver information processing errors (e.g., looked but did not see) or errors in dynamic judgment (e.g., gap distances). OV-CR MV crashes represent a quasi- (or perhaps pseudo-) control condition where there was no truck driver critical error or other critical truck failure. OV drivers did make critical errors in these crashes, however, and comparisons of their errors to those of truck drivers reveal similarities as well as important differences.

The original study found few important differences between CTs and STs in their crash causal profiles or other characteristics. Far more revealing were comparisons among the three crash categories presented here. Two general types of results are presented for the three categories:

- Comparisons of CR profiles for all LTCCS crashes where a CR was assigned.

- Comparisons of other characteristics, conditions of occurrence, and associated factors (for aggregated CT + ST crash involvements, representing $\sim 98 \%$ of LTCCS trucks).

\section{RESULTS \& DISCUSSION: COMPARISONS OF CRASH CR PROFILES}

The LTCCS critical reason (CR) was the immediate reason, failure, or human error leading to the crash critical event, which was the vehicle action or event that made the crash unavoidable, or was the crash itself. In its publications (e.g., Starnes, 2006), FMCSA avoids the words "cause" and "fault." Nevertheless, the CR may be considered the principal proximal cause or trigger of the crash, and drivers/vehicles assigned the CR would, overwhelmingly, be legally at-fault for their crashes. Moreover, because the LTCCS recorded no causes or reasons judged to be contributory, the CR is the sole documented cause of LTCCS crashes. Other factors are merely associated, even though users are likely to draw causal inferences from them, as when "driver fatigue" is coded as an associated factor.

Table 1 presents the top ten CRs for each of the three crash categories, as well as their column percentages and top-ten ranks within each category. The 14 CRs shown encompass the top ten for each of the three categories and at least $96 \%$ of CRs assigned in each category. Driving too fast was the dominant CR for truck SV crashes, and high on the list for both categories of MV crashes as well. Two categories of recognition failure, inattention (encompassing several subcategories) and inadequate surveillance ("looked but did not see"), were dominant in MV crashes and significant in SV crashes as well. Asleep-at-the-wheel was the proximal cause of $13 \%$ of truck SV crashes, $9 \%$ of OV-CR MV crashes, but only 1\% of truck-CR MV crashes. Correcting for rounding error, OV drivers were eight times more likely to be asleep-at-the-wheel 
than truck drivers in their MV crashes. Heart attacks and other physical impairments presented a similar picture, though the OV/truck ratio was less extreme, about 3:1.

Table 1. Top critical reasons (CRs) for three categories of LTCCS truck crashes

\begin{tabular}{|c|c|c|c|}
\hline Critical Reasons (includes some aggregations) & $\begin{array}{l}\text { Truck } \\
\text { SV \% }\end{array}$ & $\begin{array}{l}\text { Trk-CR } \\
\text { MV \% }\end{array}$ & $\begin{array}{l}\text { OV-CR } \\
\text { MV \% }\end{array}$ \\
\hline Too fast for conditions or curve/turn** & $30 \%(1)$ & $13 \%(3)$ & $10 \%(4)$ \\
\hline Asleep-at-the-wheel & $13 \%(2)$ & $1 \%$ & $9 \%(5)$ \\
\hline Vehicle failure (e.g., cargo shift, brakes, tires, suspension) ${ }^{* * *}$ & $13 \%(3)$ & $7 \%(6)$ & $4 \%(10)$ \\
\hline Inattention (e.g., distraction, daydreaming)* & $13 \%(4)$ & $19 \%(1)$ & $20 \%(1)$ \\
\hline Response execution error (e.g., overcompensation, poor control) & $8 \%(5)$ & $3 \%(10)$ & $9 \%(6)$ \\
\hline Heart attack or other physical impairment & $6 \%(6)$ & $2 \%$ & $6 \%(8)$ \\
\hline Inadequate surveillance (looked but did not see or didn't look) & $4 \%(7)$ & $19 \%(2)$ & $10 \%(2)$ \\
\hline Driver error, type unknown & $4 \%(8)$ & $4 \%(8)$ & $10 \%(3)$ \\
\hline Aggressive driving behavior & $2 \%(9)$ & $0.5 \%$ & $2 \%$ \\
\hline Environmental factor (e.g., slick roads, weather, roadway)**** & $2 \%(10)$ & $3 \%$ & $3 \%$ \\
\hline Illegal maneuver & $0.4 \%$ & $8 \%(4)$ & $7 \%(7)$ \\
\hline Following too closely to respond to unexpected actions & $0.4 \%$ & $8 \%(5)$ & $1 \%$ \\
\hline Misjudgment of gap or other's speed & $0.2 \%$ & $5 \%(7)$ & $4 \%(9)$ \\
\hline False assumption of other road user actions & $0.0 \%$ & $3 \%(9)$ & $2 \%$ \\
\hline Other miscellaneous CRs not shown & $2 \%$ & $4 \%$ & $3 \%$ \\
\hline Total & $100 \%$ & $100 \%$ & $100 \%$ \\
\hline
\end{tabular}

Aggregations: * Internal distraction, + external distraction, + other inattention (daydreaming), + unknown recognition error. $* *$ Too fast for conditions to be able to respond to unexpected actions of other road users, + too fast for curve/turn. *** All vehicle factor CRs combined. ${ }^{* * *}$ All environmental CRs combined. Percentages are LTCCS estimates of all serious U.S. truck crashes.

Table 1 demonstrates that truck SV and MV crashes result from largely different profiles of proximal causes. Truck SV crashes are dominated by speeding and catastrophic failures of the driver or vehicle, resulting in some form of vehicle control loss. Truck-CR MV crashes can be due to these CRs, but more often they are due to recognition failures or decision errors made in relation to other vehicles, such as a gap misjudgment or the "decision" to follow too closely. The fact of disparate CR profiles for truck SV and truck-CR MV crashes suggests that combining them into an "all truck-CR" category is "mixing apples and oranges," and likely to mask underlying crash causal profiles and mechanisms. SV-MV crash differences may not be widely appreciated, but they are not surprising given that SV crashes involve a failure of vehicle control, whereas MV crashes reflect primarily a failure of response to traffic events (Knipling, 2009).

The two MV CR profiles are similar. This is to be expected, since both reflect primarily vehicle interaction errors rather than loss of vehicle control. Some truck-OV differences are notable. Inadequate surveillance is more prominent for trucks (19\%) than OVs $(10 \%)$, probably because of blind zones and other visibility problems for trucks. Trucks also have more vehicle factors that can go wrong (7\% vs. $4 \%$ ). Trucks following OVs too closely represented a greater threat $(8 \%)$ for LTCCS crashes than OVs following trucks (1\%), probably because of truck brake limitations and the high forces resulting from truck impacts into smaller vehicles. 
Of the three categories, one might expect the first (truck SV) and third (OV-CR MV) to be least similar, since they ostensibly share no common elements. They are different crash categories, and a different vehicle has the CR. In fact, the two most dissimilar categories are the first two, truck SV crashes and truck-CR MV crashes. This was demonstrated by two correlational comparison methods, as shown in Table 2. Both methods showed truck SV profiles to be more similar to OV-CR MV profiles than to truck-CR MV profiles. The two comparison methods differ as to which two profiles are most similar.

Table 2. Dyad comparisons of the three categories using two correlation methods

\begin{tabular}{|l|c|c|c|}
\hline Correlation Method & $\begin{array}{c}\text { Trk SV } \times \\
\text { Trk-CR MV }\end{array}$ & $\begin{array}{c}\text { Trk SV } \times \\
\text { OV-CR MV }\end{array}$ & $\begin{array}{c}\text { Trk-CR MV } \times \\
\text { OV-CR MV }\end{array}$ \\
\hline Pearson r comparing all 34 possible specific CRs & $+\mathbf{0 . 1 8}$ & $+\mathbf{0 . 3 5}$ & $+\mathbf{0 . 6 6}$ \\
\hline Spearman rho comparing ranks of 14 CRs in Table 1 & $+\mathbf{0 . 0 9}$ & $+\mathbf{0 . 5 8}$ & $+\mathbf{0 . 4 6}$ \\
\hline
\end{tabular}

Is there a plausible explanation for the above finding? The finding can be understood in light of the fact that many serious truck-light vehicle crashes involve the same kinds of light vehicle driver unsafe driving acts and impairments seen in SV crashes. The statistics in Table 1 belie this. To the extent that OV-CR MV crashes are like SV crashes, they cannot be successfully addressed by public information messages like "Share the Road" and "Don't Hang Out in the No Zone." For MV crashes involving light vehicle driver CRs but SV-like crash scenarios, the truck is merely the impact point for the errant light vehicle. Such crashes are better addressed by mainstream traffic safety (e.g., the " 4 E's" of engineering, education, enforcement, and emergency response) than by programs focusing on light vehicle-truck interaction, like "Share the Road." On the other hand, to the extent that OV-CR MV crashes do represent vehicle interaction errors like "cutting in," such programs may have value, or at least a rationale.

\section{RESULTS \& DISCUSSION: COMPARISONS OF OTHER CHARACTERISTICS}

This section examines characteristics are associated with the three categories. Tables 3-6 compare descriptions, conditions of occurrence, and other factors associated with the three categories, plus the baseline total for all truck involvements (the weighted average of the three). Each percentage is for the attribute within that variable, and coded in relation to the truck or truck driver. They are based on truck crash involvements rather than crashes. For example, in Table 3 truck crash involvements occurring between 4:01 and 7:00am were 11\% of all CT+ST involvements, $24 \%$ of SV involvements, $4 \%$ of truck-CR MV involvements, and $8 \%$ of OV-CR MV involvements. Is there an explanation for the overinvolvement of these three hours in SV crashes? These hours are within the lowest circadian valley of the 24-hour day for human performance (Rosekind, 2005; Knipling, 2009), and SV crashes are the category most reflective of driver performance failure. Hours-of-sleep and time awake are two other physiological parameters affecting performance, and show similar relative effects in Table 3. Not surprisingly, the variable "Driver Fatigue" is also similar, though it had a less objective basis for investigator coding than the other three variables cited. Looking down to Table 6, we see that not every reputed fatigue factor has such crash involvement patterns. Long hours of working and driving (within the legal limits at the time) have no consistent association with crash pattern. Many sleep 
and safety researchers (e.g., Rosekind, 2005; Knipling, 2009) consider such non-physiologicallybased HOS work parameters to be only weakly related to crash risk and involvement.

Table 3. Factors associated with SV (and perhaps MV Trk-CR) involvements

\begin{tabular}{|l|l|c|c|c|c|}
\hline LTCCS Variable & Attribute (or Attribute Aggregation) & $\begin{array}{c}\text { Total } \\
\text { CT+ST } \\
\%\end{array}$ & SV\% & $\begin{array}{c}\text { MV } \\
\text { Trk-CR\% }\end{array}$ & $\begin{array}{c}\text { MV } \\
\text { OV-CR\% }\end{array}$ \\
\hline Hour-of-Day & $\mathbf{4 : 0 1}$ to 7:00am & $\mathbf{1 1 \%}$ & $\mathbf{2 4 \%}$ & $\mathbf{4 \%}$ & $\mathbf{8 \%}$ \\
\hline Relation to Junction & Entrance/exit ramp related & $\mathbf{1 1 \%}$ & $\mathbf{2 2 \%}$ & $\mathbf{7 \%}$ & $\mathbf{7 \%}$ \\
\hline Trafficway Flow & $\begin{array}{l}\text { Undivided (2-way w/ or w/o left turn } \\
\text { lane) or one-way }\end{array}$ & $\mathbf{4 2 \%}$ & $\mathbf{5 8 \%}$ & $\mathbf{3 7 \%}$ & $\mathbf{3 6 \%}$ \\
\hline Posted Speed Limit & $\mathbf{7 0}$ or 75mph & $\mathbf{1 1 \%}$ & $\mathbf{1 6 \%}$ & $\mathbf{6 \%}$ & $\mathbf{8 \%}$ \\
\hline Road Alignment & Curve (Left + Right) & $\mathbf{3 0 \%}$ & $\mathbf{6 0 \%}$ & $\mathbf{2 2 \%}$ & $\mathbf{1 9 \%}$ \\
\hline $\begin{array}{l}\text { Pre-Event Movement } \\
\text { (Truck) }\end{array}$ & Truck negotiating a curve & $\mathbf{2 8 \%}$ & $\mathbf{4 6 \%}$ & $\mathbf{1 2 \%}$ & $\mathbf{9 \%}$ \\
\hline $\begin{array}{l}\text { Seat Belt [Non-] Use (by } \\
\text { Truck Driver) }\end{array}$ & None used or not indicated & $\mathbf{1 1 \%}$ & $\mathbf{2 3 \%}$ & $\mathbf{8 \%}$ & $\mathbf{6 \%}$ \\
\hline $\begin{array}{l}\text { Driver Roadway } \\
\text { Familiarity }\end{array}$ & $\begin{array}{l}\text { Truck driver rarely/never drove } \\
\text { road before* }\end{array}$ & $\mathbf{2 6 \%}$ & $\mathbf{3 8 \%}$ & $\mathbf{2 9 \%}$ & $\mathbf{1 7 \%}$ \\
\hline Vehicle Factor (Truck) & Present (any inspection deficiency) & $\mathbf{4 0 \%}$ & $\mathbf{6 2 \%}$ & $\mathbf{5 0 \%}$ & $\mathbf{2 1 \%}$ \\
\hline Roadway Factor & Present (any deficiency) & $\mathbf{2 0 \%}$ & $\mathbf{2 7 \%}$ & $\mathbf{2 1 \%}$ & $\mathbf{1 7 \%}$ \\
\hline Driver Fatigue & Truck driver fatigued* & $\mathbf{1 3 \%}$ & $\mathbf{3 5 \%}$ & $\mathbf{1 7 \%}$ & $\mathbf{3 \%}$ \\
\hline Hours of Last Sleep & $<6$ hours last main sleep* & $\mathbf{1 6 \%}$ & $\mathbf{2 9 \%}$ & $\mathbf{1 5 \%}$ & $\mathbf{1 0 \%}$ \\
\hline Hours Since Last Sleep & $\mathbf{1 6 +}$ Hours (as \% of 0 to 18+)* & $\mathbf{3 . 4 \%}$ & $\mathbf{6 . 3 \%}$ & $\mathbf{3 . 5 \%}$ & $\mathbf{1 . 6 \%}$ \\
\hline
\end{tabular}

* \% of knowns. Table 3-6 percentages are LTCCS estimates for all U.S. CTs + STs involved in serious crashes.

Other comparisons seen in Table 3 demonstrate that a variety of factors contribute to crash causation. Safety belt non-use is not a driving behavior, but it is indicative of risk-related driver personality traits like lack of conscientiousness. It may also be linked to driver fatigue since obese drivers are at-risk for sleep apnea and also have low belt use rates (Knipling, 2009). Driver roadway unfamiliarity is a temporary driver state affecting attention to driving. Vehicle deficiencies may affect vehicle braking or other performance, and also may be correlated with other unsafe driver or carrier practices. Several roadway factors (e.g., curves) are seen to elevate SV crash risk. Note in Table 3 that some factors associated with truck SV crashes appear also to have weaker associations with truck-CR MV crashes compared to OV-CR MV crashes. A newly-published LTCCS analysis report (Hallmark et al., 2009) corroborates many of the SV crash features shown in Table 3 and elsewhere in this paper.

For truck-CR MV involvements (Table 4), the culprits are mostly those relating to driving in dense traffic, such as urban driving and rush hours. In Table 5, the sharpest overinvolvement of OV-CR MV crashes is seen in fatal crashes, the highest of three LTCCS severity levels. Looking at the severity statistics from another perspective (not shown in the tables), trucks were assigned the CR in $23 \%$ of their fatal (K) MV crash involvements, $37 \%$ of their incapacitating injury (A) MV crashes, and $46 \%$ of their non-incapacitating injury (B) MV crashes. 
Table 4. Factors associated with MV Trk-CR (vs. MV OV-CR) involvements

\begin{tabular}{|l|l|c|c|c|c|}
\hline LTCCS Variable & Attribute (or Attribute Aggregation) & $\begin{array}{c}\text { Total } \\
\text { CT+ST } \\
\%\end{array}$ & SV\% & $\begin{array}{c}\text { MV } \\
\text { Trk-CR\% }\end{array}$ & $\begin{array}{c}\text { MV } \\
\text { OV-CR\% }\end{array}$ \\
\hline Hour-of-Day & $\begin{array}{l}\text { Rush hours } \\
\text { (7:01 to 10:00am, 4:01 to 7:00pm) }\end{array}$ & $\mathbf{3 1 \%}$ & $\mathbf{2 3 \%}$ & $\mathbf{4 4 \%}$ & $\mathbf{2 6 \%}$ \\
\hline Relation to Junction & Intersection & $\mathbf{1 5 \%}$ & $\mathbf{9 \%}$ & $\mathbf{2 3 \%}$ & $\mathbf{1 4 \%}$ \\
\hline $\begin{array}{l}\text { Trafficway Functional } \\
\text { Class }\end{array}$ & Urban (6 different roadway types) & $\mathbf{5 2 \%}$ & $\mathbf{3 8 \%}$ & $\mathbf{6 5 \%}$ & $\mathbf{5 3 \%}$ \\
\hline $\begin{array}{l}\text { Attempted Avoidance } \\
\text { Maneuver }\end{array}$ & $\begin{array}{l}\text { Yes (braking, steering, and/or } \\
\text { accelerating) }\end{array}$ & $\mathbf{6 2 \%}$ & $\mathbf{5 9 \%}$ & $\mathbf{6 4 \%}$ & $\mathbf{4 7 \%}$ \\
\hline Traffic Factors & Present & $\mathbf{2 7 \%}$ & $\mathbf{6 \%}$ & $\mathbf{4 2 \%}$ & $\mathbf{3 1 \%}$ \\
\hline
\end{tabular}

$* \%$ of knowns.

Table 5. Factors associated with MV OV-CR (vs. MV Trk CR) involvements

\begin{tabular}{|l|l|c|c|c|c|}
\hline LTCCS Variable & Attribute (or Attribute Aggregation) & $\begin{array}{c}\text { Total } \\
\text { CT+ST } \\
\mathbf{\%}\end{array}$ & $\begin{array}{c}\text { SV\% } \\
\text { Crash Severity }\end{array}$ & $\begin{array}{c}\text { MV } \\
\text { Trk-CR\% }\end{array}$ & $\begin{array}{c}\text { MV } \\
\text { OV-CR\% }\end{array}$ \\
\hline Hour-of-Day & Fatal crash & $\mathbf{9 \%}$ & $\mathbf{3 \%}$ & $\mathbf{6 \%}$ & $\mathbf{1 4 \%}$ \\
\hline Light Condition & $\mathbf{7 : 0 1 p m}$ to 4:00am & $\mathbf{1 6 \%}$ & $\mathbf{1 6 \%}$ & $\mathbf{1 3 \%}$ & $\mathbf{1 9 \%}$ \\
\hline
\end{tabular}

Table 6. Factors without strong SV or MV Trk-OV differential association

\begin{tabular}{|c|c|c|c|c|c|}
\hline LTCCS Variable & Attribute (or Attribute Aggregation) & $\begin{array}{c}\text { Total } \\
\text { CT+ST } \\
\%\end{array}$ & SV\% & $\begin{array}{c}\text { MV } \\
\text { Trk-CR\% }\end{array}$ & $\begin{array}{c}\text { MV } \\
\text { OV-CR\% }\end{array}$ \\
\hline $\begin{array}{l}\text { Roadway Surface } \\
\text { Condition }\end{array}$ & Wet & $16 \%$ & $13 \%$ & $16 \%$ & $18 \%$ \\
\hline Construction Work Zone & Present (in zone) & $13 \%$ & $3 \%$ & $18 \%$ & $17 \%$ \\
\hline Weather Factor & Present (adverse weather) & $14 \%$ & $12 \%$ & $15 \%$ & $15 \%$ \\
\hline $\begin{array}{l}\text { Hours Driving Since 8-Hr } \\
\text { Break }\end{array}$ & $\begin{array}{l}\text { 7-10 Hours driving } \\
\text { (as \% of } 0 \text { to } 10 \text { ) }\end{array}$ & $11 \%$ & $13 \%$ & $10 \%$ & $11 \%$ \\
\hline $\begin{array}{l}\text { Hours On-Duty Since 8- } \\
\text { Hr Break }\end{array}$ & $\begin{array}{l}\text { 10+ Hours on-duty } \\
\text { (as \% of } 0 \text { to } 14+\text { ) }\end{array}$ & $6.3 \%$ & $6.9 \%$ & $4.9 \%$ & $6.6 \%$ \\
\hline $\begin{array}{l}\text { Hours Worked Since 8-Hr } \\
\text { Break }\end{array}$ & $\begin{array}{l}\text { 10+ Hours working } \\
\text { (as \% of } 0 \text { to } 14+\text { ) }\end{array}$ & $6.7 \%$ & $5.2 \%$ & $8.1 \%$ & $6.4 \%$ \\
\hline
\end{tabular}

Table 6 presents factors generally without strong differential associations. A factor like "wet roads" may raise crash risk, but it does so almost uniformly across categories. LTCCS work zone percentages are far in excess of exposure to work zones, which is about $1 \%$ of driving (Knipling, 2009). But they don't suggest greater likelihood of fault for trucks compared to other vehicles in their MV crashes. Both MV percentages greatly exceed the SV percentage, however.

Corresponding pairs of percentages in Tables 1 and 3-6 can be compared to generate relative risk ratios or odds ratios. For example, in Table 4 the relative risk of truck-CR in MV crashes during rush hours is simply $0.44 / 0.26$ or $\mathbf{1 . 7}$. The same odds ratio would be $(0.44 / 0.56) /(0.26 / 0.74)=$ 2.2. Comparing one category to the other two categories combined (i.e., the rest of the dataset) requires more extensive calculations and knowledge of the percentage of each of the three categories. For Table 1 (truck crashes), the LTCCS percentages were SV (31\%), MV Truck-CR 
(34\%), and MV OV-CR (35\%). For Tables 3-6 (CT+ST involvements), the respective percentages were $27 \%, 29 \%$, and $44 \%$. For example, the relative risk ratio of "SV crash involvement, given non-belt use" was $\mathbf{3 . 5}$ and the corresponding odds ratio was $\mathbf{4 . 3}$ (calculations not shown). Such relative risk and odds ratios do not capture crash risk, however. Rather, they represent crash category risk, a big difference. Quantification of crash risk requires non-crash control or exposure data, which did not exist in the LTCCS. Perhaps future crash investigation studies will find a way to correct this deficiency, and thereby strengthen crash causal inference.

\section{ACKNOWLEDGMENTS}

The original project generating the data for this paper was funded by FMCSA and performed under a Virginia Tech Transportation Institute (VTTI) subcontract. Ralph Craft of FMCSA was the DOT project manager. Joe Bocanegra of VTTI performed the LTCCS data retrievals.

\section{REFERENCES}

Hallmark, S.L., Hsu, Y-Y, Maze, T., McDonald, T., and Fitzsimmons, E. (2009). Investigating Factors Contributing to Large Truck Crashes Using the FMCSA's LTCCS Database. Center for Transportation Research and Education, Iowa State Univ., FMCSA report.

Knipling, R.R. (2009). Safety for the Long Haul: Large Truck Crash Risk, Causation, \& Prevention. Arlington, VA: American Trucking Associations.

Knipling, R.R. and Bocanegra, J. (2008). Comparison of Combination-Unit Truck and SingleUnit Truck Statistics from the LTCCS. Washington, DC: FMCSA \& Volpe Center.

Rosekind, M.R. (2005). Managing Safety, Alertness and Performance through Federal Hoursof-Service Regulations: Opportunities and Challenges. Alertness Solutions. FMCSA rulemaking docket \#FMCSA-2004-19608.

Starnes, M. (2006) LTCCS: An Initial Overview. NHTSA National Center for Statistics \& Analysis, DOT HS 810 646, August 2006. 